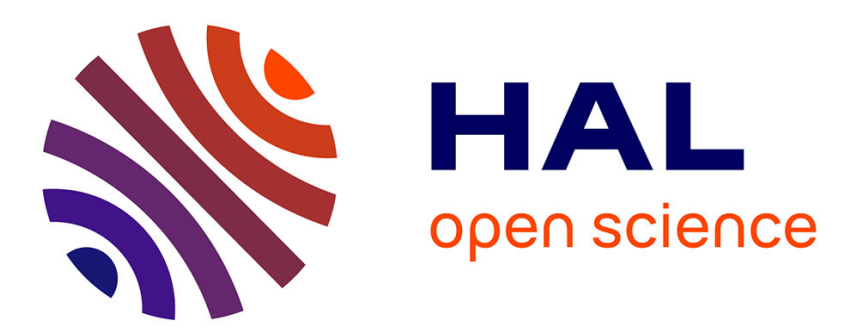

\title{
Research and Application of Safety Management for Virtual Desktop in Colleges and Universities
}

\author{
Haifeng Jia, Guifen Chen
}

\section{To cite this version:}

Haifeng Jia, Guifen Chen. Research and Application of Safety Management for Virtual Desktop in Colleges and Universities. 11th International Conference on Computer and Computing Technologies in Agriculture (CCTA), Aug 2017, Jilin, China. pp.9-23, 10.1007/978-3-030-06137-1_2 . hal-02124246

\section{HAL Id: hal-02124246 \\ https://inria.hal.science/hal-02124246}

Submitted on 9 May 2019

HAL is a multi-disciplinary open access archive for the deposit and dissemination of scientific research documents, whether they are published or not. The documents may come from teaching and research institutions in France or abroad, or from public or private research centers.
L'archive ouverte pluridisciplinaire HAL, est destinée au dépôt et à la diffusion de documents scientifiques de niveau recherche, publiés ou non, émanant des établissements d'enseignement et de recherche français ou étrangers, des laboratoires publics ou privés. 


\title{
Research and Application of Safety Management for Virtual Desktop in Colleges and Universities
}

\author{
Haifeng Jia, Guifen Chen ${ }^{(凶)}$ \\ CLC number: TP393 Document code: A \\ College of Information and Technology Science, Jilin Agricultural University, \\ Changchun, Jilin 130118 \\ guifchen@163.com
}

\begin{abstract}
In the view that the traditional PC desktop management model can not meet the demand of teaching resources in colleges and universities, this paper introduces the cloud desktop technology into the teaching resource management of colleges and universities to improve the utilization rate of the teaching resources and the management level of the staff. In this paper, the author builds a 900-point cloud desktop system platform by using the cloud server and thin terminal of Huawei. Based on the virtualization technology and cloud computing security model, it realizes the unity of cloud desktop, resource sharing and ensures the security and remote control of data. The test application was carried out in the teaching and management of the training center on the cloud. Result of application indicates that cloud desktop is more efficient, convenient and safer than traditional PC in resource utilization, network requirements, hardware configuration, energy saving management and use of the model, and it also has a huge development advantages.
\end{abstract}

Keywords. Cloud desktop · Virtualization · Sharing · Security · Management

\section{Introduction}

The cloud desktop is a solution which is used to the replace PC. Desktop computing terminals are no longer using computer hosts, instead of computing power. The cloud desktop realizes the unity of the desktop and the sharing of resources through the cloud computing software. Therefore, the use of display and cloud terminal devices can achieve login, office, teaching and etc. ${ }^{[18]}$.In the view of virtual desktop overall system point, the client, transmission network, server, storage and other aspects, will have a security risk. Ignoring any details can lead to information loopholes in the entire system. As cloud computing provides maximum convenience for users and enterprises to use storage resources, software resources, and computing resources at a low cost, the biggest challenge to it, or the problem of it, comes from security. Security issues such as security boundaries, application security, cloud computing abuse, abuse, denial of service attacks, insecure interfaces and APs, shared technology issues, data leakage, account numbers, and service hijacking are particularly important.

The desktop cloud platform provides desktop services to end users through the virtual desktop architecture ${ }^{[7]}$. VDI is a combination of remote desktop connectivity and virtualization technology. Through server virtualization technology, it runs multiple virtualized hosts on a physical server. Each virtualized host has independent computing, network, software and other resources, installing and running their own client operating system. Such as Windows7, Windows XP or Linux. Each virtual machine is independent of each other without affecting. 
Users connect to the virtual machine remotely via the desktop transport protocol and get their desktop environment users local terminals or PCs only by running a remote desktop connection client program to get complete computer software and systems and other resources ${ }^{[32]}$. Cloud desktop in the performance of centralized management, resource sharing, high efficiency operating advantages at the same time, its complex system management problems, the problem of the resources are difficult to effectively use, security issues, also plagued IT administrators. The author analyzes the construction, operation management and maintenance of cloud desktop in the virtual simulation training center of Changchun University of Finance and Economics, summarizes the mainstream cloud desktop security management technology at home and abroad and designs the corresponding cloud management model according to the unit's own situation ${ }^{[33]}$.

\section{The key technologies of cloud desktop management}

Technology of cloud desktop management involves in Web technology, cloud computing virtualization technology, data mining and other technologies. Therefore, the cloud desktop management technology has many problems to study, the most basic is the platform monitoring technology, resource optimization technology and security technology. The following is a brief introduction to the three aspects combined with the Institute of practical training center ${ }^{[3]}$.

\section{1monitoring the desktop virtual terminal, simplifying the management model}

The desktop system is more complex and consists of several components, such as server, storage, and network. There are multiple management terminals, each of which is difficult to have a clear understanding of the system; Fault location is difficult, and it is necessary to analyze multiple systems to solve the problem.

The virtualization technology of cloud desktop uses the background cloud server to perform the monitoring and management of the performance of the CPU, memory, terminal, network and other aspects of the virtual terminal. Through detailed data monitoring, it can effectively manage the resource utilization problems existing in terminal use, ensure that the cloud desktop platform has the maximum limit and optimal use system resources. when using the CPU resource footprint, insufficient memory and the virtual hard disk space in the platform virtual desktop, it can quickly make the intuitive response to the purpose of the warning. Platform monitoring interface shown in Figure1.

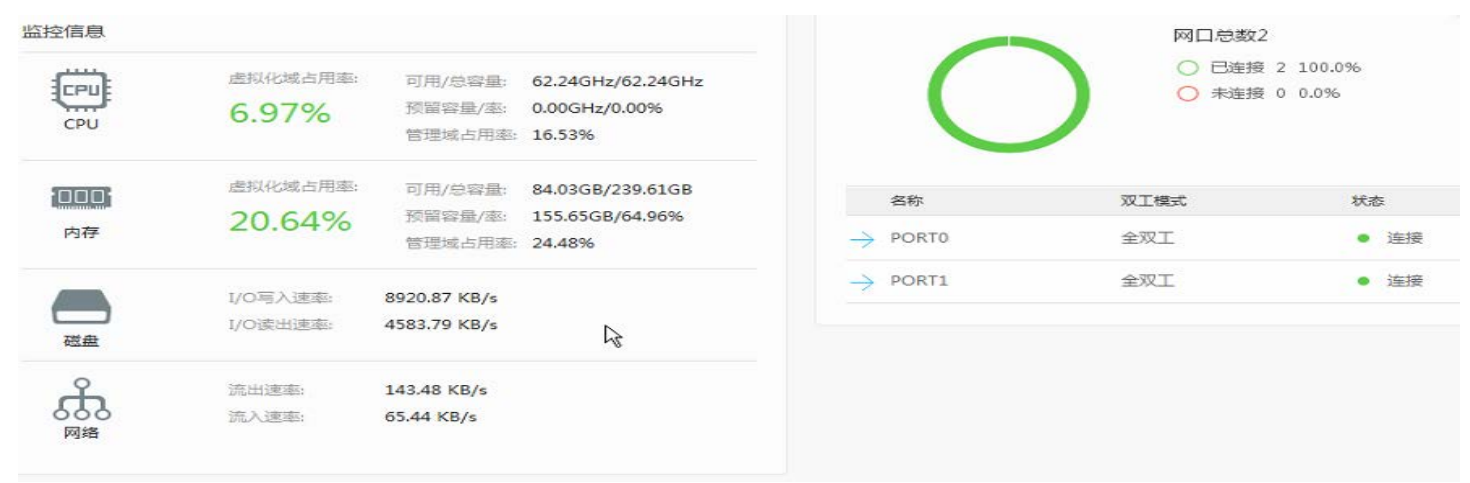

Figure.1. The cloud desktop platform monitoring of the Institute training center

\subsection{Monitoring the virtual desktop environment to improve utilization of}




\section{resource}

It is difficult to management the desktop cloud resource: resource allocation is difficult to do effective management. With a long time running of the cloud desktop system, virtual resources can not be effectively used. For example: If cloud desktop does not shut down for a long time, virtual resources can not been recycled, resources are not enough to be allocated for a large part of other virtual desktops, resulting in a serious resource idle and waste.

Monitoring the usage of the virtual host, storage, virtual machine through the background management terminal and analyzing statistics, resource recycling is carried out by the virtual machine that distributes the resources in excess, the resource allocation is increased to the virtual machine with insufficient resource allocation, and the overall environment and the user experience is improved.Virtualization resource management interface is shown in Figure2.

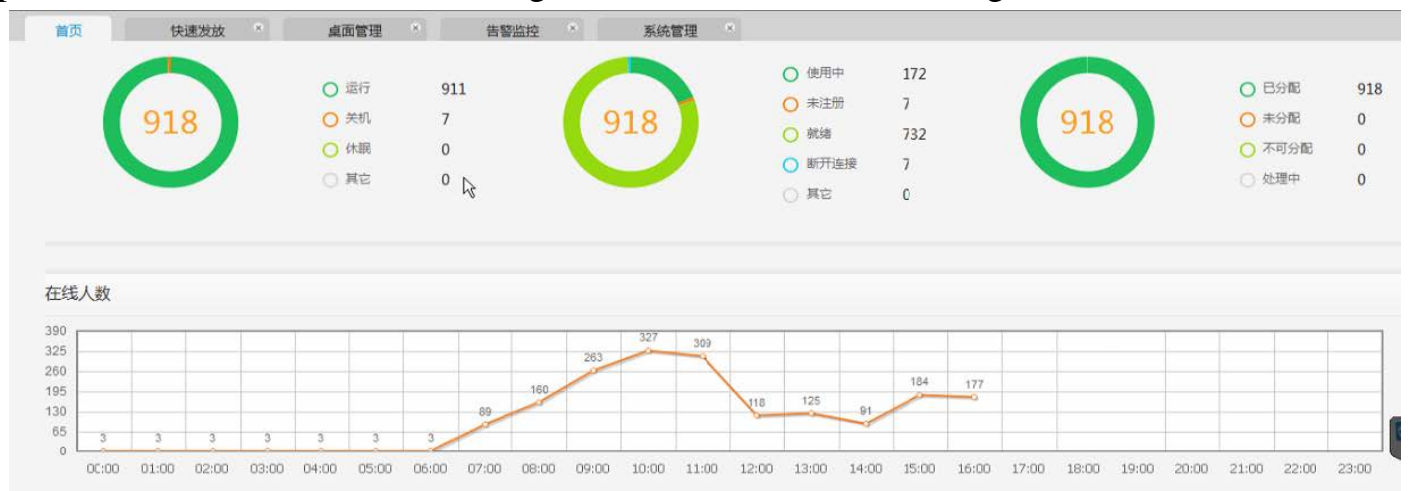

Figure. 2. Virtualization Resource Management of the Institute training center

\subsection{Auditing the user behavior of the virtual desktop, ensuring system security}

It is difficult for desktop cloud security audit: It is difficult to audit illegal login behavior,as virtual desktop login behavior is lack of control

Virtual desktop operating behavior lacks control, it is difficult to audit illegal operation behavior.

When the operator operates the key equipment (server, secret machine), he will record the operation of the screen image recording;while the screen element information is also recorded at the same time; Auditors are audited on the server by looking at audit records.Log audit management records for system run are shown in Figure3.

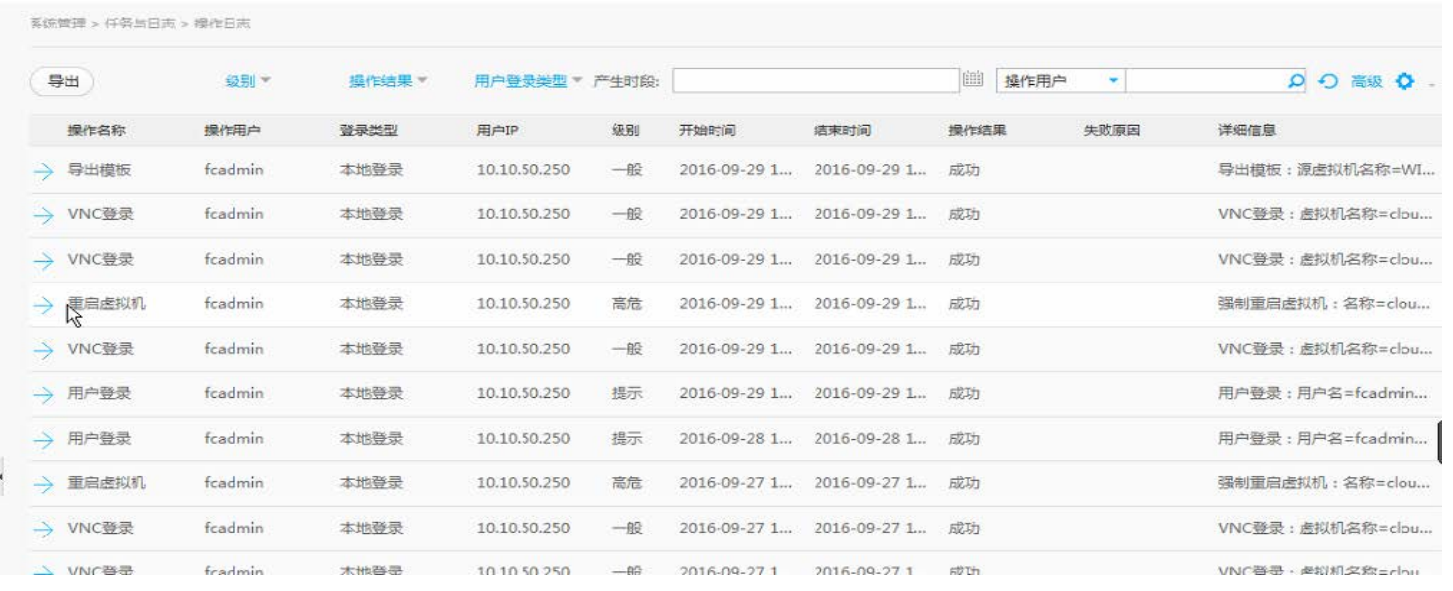

Figure. 3. The user behavior audit logmanagement of the Institute training center

\section{The build and design scheme of cloud desktop platform.}




\subsection{The overall architecture and planning of the platform}

Based on the Center's teaching and office planning, we will plan to build the cloud desktop system platform of the 900-points in the center. The platform adopts Huawei's cloud server and cloud thin terminal, the user goes through the terminal and protocol ofthe desktop display to accessaddress or portal of the cloud desktop, the access address or portal generally preload the load balancing device ${ }^{[20]}$. The user manage server, going through management system of the user,to verify the user identityusually by Microsoft's AD (Active Directory), the request is directed to a random or custom cloud desktop after the authentication. Then the user logs in the cloud desktop, he or she visits the business system as if he logged on to the local desktop ${ }^{[34]}$. According to the above plan described the infrastructure shown in Figure4.

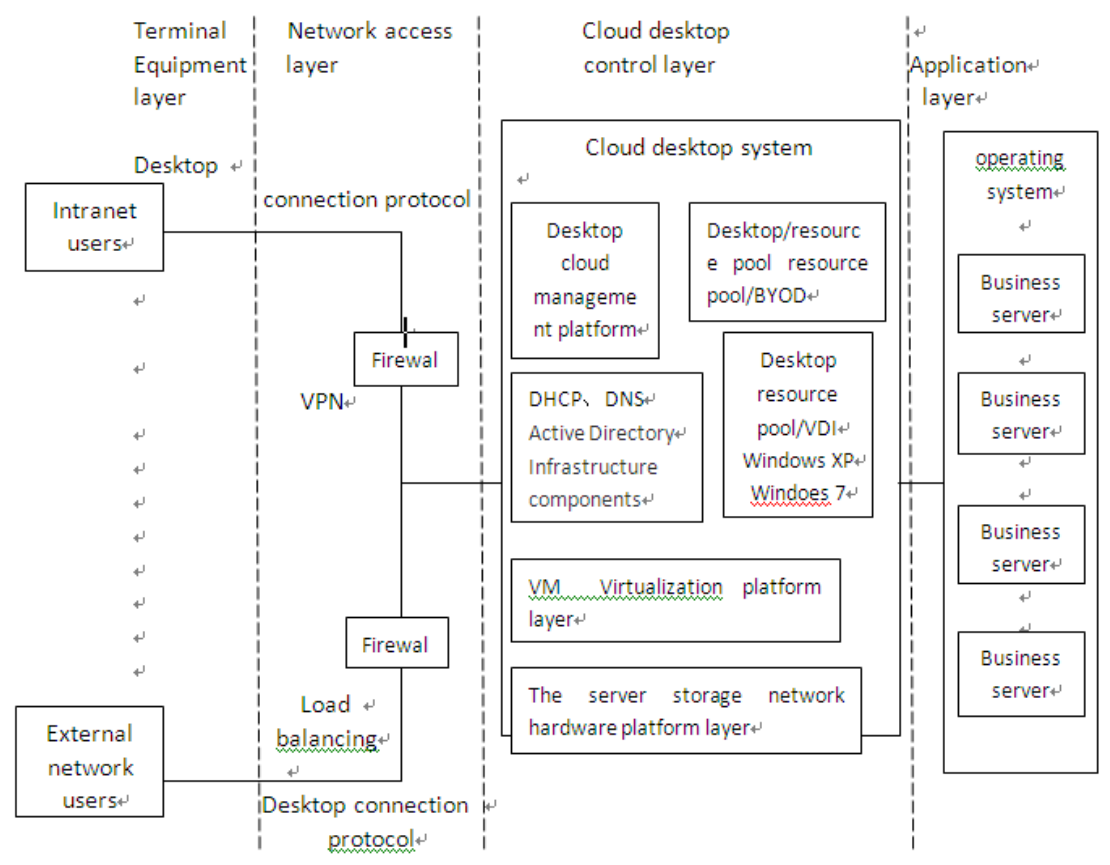

Figure. 4. Schematic diagram of the cloud desktop infrastructure

\subsection{The IP address design of overall network planning and information.}

Based on the number of the above-mentioned architecture and information points to plan the network topology of the planning center, for each information thin terminal allocation of resources and fixed IP address so that the background cloud server-side seamless docking. Network topology planning specific description:

(1). All terminals can access the Internet, going through core switch of the campus network leads to an interface to connect the export firewallof the training center,all the address of the training center will be interconnected with campus network and Internet by the default route.

(2) The uplink of internal core switch of the training center is connected with the firewall, and the downlink is connected to the access switch of each terminal directly through the multimode fiber link. At the same time, the CE5855 switch is connected with the 10GE port, and the CE5855 switch is connected withthe service interfaceof each server.

(3). Two CE5855 switches to be stacked,are interconnected with the core switch at the same time, and configure the link aggregation.

(4). Network management software to manage all the network equipment. The network topology scheme is shown in Figure 5. 


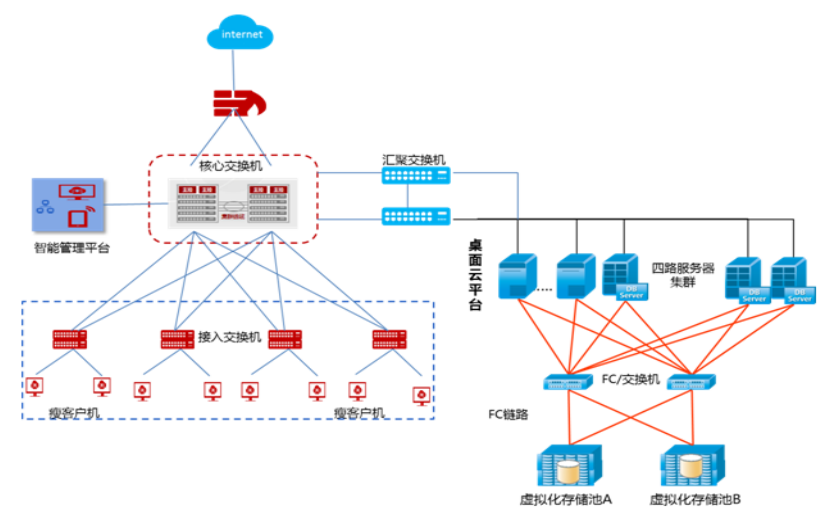

Figure.5. The cloud desktop platform network topology diagram of Changchun University of Financeand Economics

\subsection{Thedesign ofplatform system IP address}

According to the network topology planning program, processing IP address design, andinformation and IP address are allocatedfor the thin terminal client .The VLAN number only valid in the training building; is forwarded by three-way routing after arriving on the campus network. The specific allocationplanin Table 1.

Table 1. Training center IP address allocation tableChangchun University of Finance and Economics

\begin{tabular}{|c|c|c|c|}
\hline VLAN ID & use & $\begin{array}{c}\text { Address } \\
\text { segment }\end{array}$ & Mask \\
\hline vlan101 & $\begin{array}{c}\text { Server management } \\
\text { cloud } \\
\text { migration }\end{array}$ & 10.10 .1 .1 & 24 \\
\hline vlan102 & Business 1 & 10.10 .2 .1 & 24 \\
\hline vlan103 & Business 2 & 10.10 .3 .1 & 24 \\
\hline vlan104 & Business 3 & 10.10 .4 .1 & 24 \\
\hline vlan105 & Business 4 & 10.10 .5 .1 & 24 \\
\hline vlan106 & Business 5 & 10.10 .6 .1 & 24 \\
\hline vlan107 & Business 6 & 10.10 .7 .1 & 24 \\
\hline vlan108 & Business 7 & 10.10 .8 .1 & 24 \\
\hline vlan109 & Business 8 & 10.10 .9 .1 & 24 \\
\hline vlan110 & Reserved & 10.10 .10 .1 & 24 \\
\hline vlan111 & Box 1 & 10.10 .11 .1 & 24 \\
\hline vlan112 & Box 2 & 10.10 .12 .1 & 24 \\
\hline vlan114 & Box 3 & 10.10 .13 .1 & 24 \\
\hline vlan115 & Box 4 & 10.10 .14 .1 & 24 \\
\hline vlan116 & Box 6 & 10.10 .15 .1 & 24 \\
\hline vlan117 & Box 7 & 10.10 .16 .1 & 24 \\
\hline vlan118 & Box 8 & 10.10 .17 .1 & 24 \\
\hline vlan119 & Box 9 & 10.10 .18 .1 & 24 \\
\hline vlan120 & Box 10 & 10.10 .19 .1 & 24 \\
\hline vlan121 & Reserved & 10.10 .21 .1 & 24 \\
\hline vlan1000 & Switch management & 10.10 .255 .1 & 24 \\
\hline vlan1001 & $\begin{array}{c}\text { Core firewall } \\
\text { interconnection }\end{array}$ & 10.10 .100 .1 & 30 \\
\hline & Firewall campus & 10.10 .110 .2 & 30 \\
\hline
\end{tabular}

\subsubsection{Set up a cloud desktop}

According to the above program for the IP and network and user configuration, to build the cloud desktop landing interface of the college training center and compared with the traditional PC desktop, as shownin Figure 6 


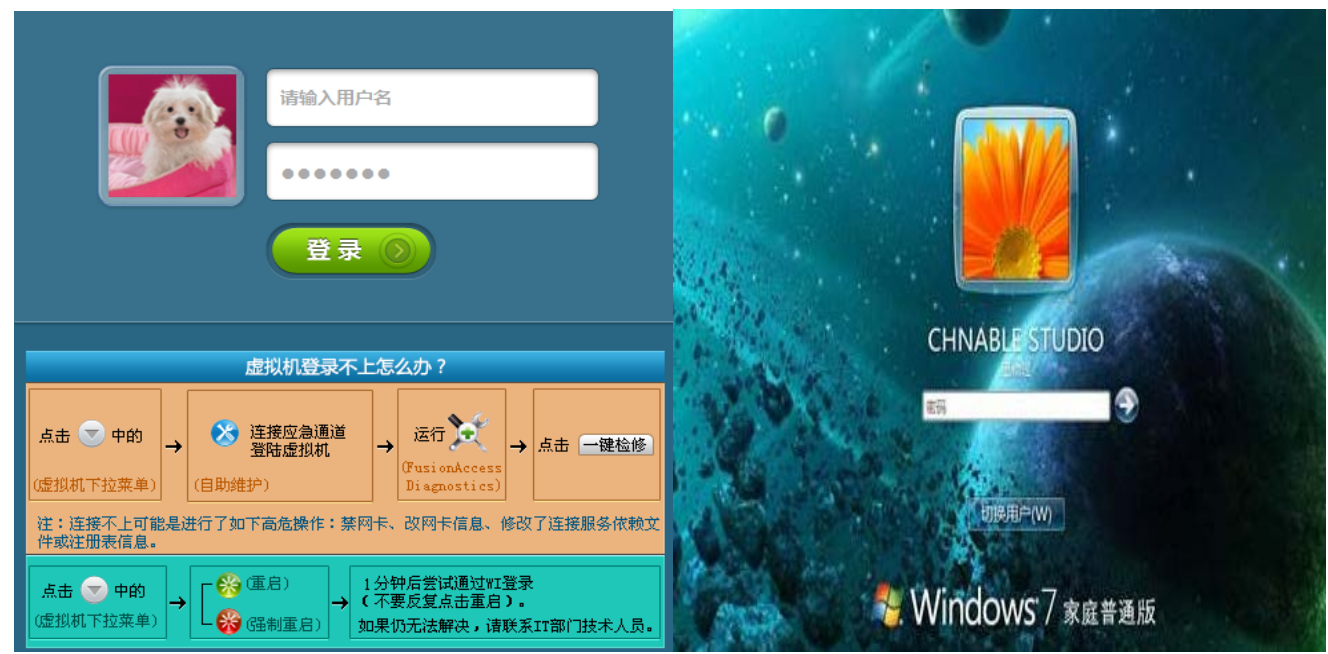

Figure. 6. Cloud desktop and traditional PC login interface in college training center

\section{Cloud Desktop Management Plan, Algorithm and Resource Scheduling Strategy}

\subsection{The Advantages of Cloud Desktop Compared with Traditional PC}

In the resource utilization, network requirements, hardware configuration and energy saving , efficient and convenient management and operating model of cloud desktop has a greater advantage than the traditional PC . Taking training room construction and traditional laboratory construction in training center of Changchun University of Finance and Economics as an example: the current standard laboratory rooms to accommodate about 96 sets of computer equipment cost about 850,000 yuan, while through the introduction of cloud terminal training room of cloud service to accommodate The number of terminals to accommodate more than 120 cost 400,000 yuan , which saves the cost and greatly enhance the efficiency of use.In the traditional room each room needs an administrator,while in the training room the entire building needs two administrators to meet the management requirements. Table 2 gives a detailed comparison.

Table 2. The comparison of advantage by cloud desktop and traditional desktop 


\begin{tabular}{|c|c|c|}
\hline P & Cloud Desktop & PC computer \\
\hline Manageability & $\begin{array}{l}\text { It is Manageable, and terminal } \\
\text { users can use all the resources, } \\
\text { but can also be strictly managed } \\
\text { using only one or several } \\
\text { programs, have greatly enhanced } \\
\text { the network management. }\end{array}$ & $\begin{array}{l}\text { The uer freedom degree } \\
\text { of is relatively large, for } \\
\text { the user's management is } \\
\text { mainly through } \\
\text { administrative means, can } \\
\text { not do desktop zero } \\
\text { management }\end{array}$ \\
\hline $\begin{array}{l}\text { On the network } \\
\text { requirements }\end{array}$ & $\begin{array}{l}\text { Only ttransmission the } \\
\text { information and mouse and } \\
\text { keyboard information of screen } \\
\text { changes, have low network } \\
\text { bandwidth requirements, a virtual } \\
\text { desktop bandwidth only need } \\
\text { about 30K - 1M. }\end{array}$ & $\begin{array}{l}\text { It is non-destabilizing } \\
\text { demand for the network } \\
\text { bandwidth it need } \\
\text { higher requirements of } \\
\text { bandwidth when the data } \\
\text { is exchanging. }\end{array}$ \\
\hline $\begin{array}{l}\text { Client hardware } \\
\text { requirements }\end{array}$ & $\begin{array}{l}\text { Low requirements for the local } \\
\text { hardware } \text { need better }^{\text {need bide. }} \\
\text { configuration for server-side. }\end{array}$ & $\begin{array}{l}\text { Higher requirements for } \\
\text { hardware, it need strong } \\
\text { support for the processor } \\
\text { and memory and hard } \\
\text { disk. }\end{array}$ \\
\hline safety & $\begin{array}{l}1 \text {, the data is not flow in the } \\
\text { network not the risk of being } \\
\text { intercepted, and the through is } \\
\text { high encryption by the } \\
\text { transmission of the screen } \\
\text { information ;2, because there is } \\
\text { no internal floppy drive, CD-ROM, } \\
\text { etc., to prevent the virus from the } \\
\text { internal system against }\end{array}$ & $\begin{array}{l}\text { 1, the data flow in the } \\
\text { network, Increase the } \\
\text { possibility of being } \\
\text { intercepted; } 2 \text {, It has great } \\
\text { mobility of the machine, } \\
\text { it provide a good tool for } \\
\text { invasion by the use of the } \\
\text { machine for malicious } \\
\text { users ; } 3 \text {, the virus is } \\
\text { easy to spread, The } \\
\text { monitoring of virus is not } \\
\text { easy. }\end{array}$ \\
\hline
\end{tabular}

\begin{tabular}{|c|l|l|}
\hline $\begin{array}{c}\text { The pressure of } \\
\text { Upgrade }\end{array}$ & $\begin{array}{l}\text { Terminal equipment does not have } \\
\text { the pressure of performance } \\
\text { small require of upgrade } \\
\text { requirements, the entire network } \\
\text { only need to upgrade the server, } \\
\text { the cycle of life is 5-10 years, } \\
\text { the upgrade pressure is small. }\end{array}$ & $\begin{array}{l}\text { Due to lack of machine } \\
\text { hardware performance } \\
\text { caused by hardware } \\
\text { upgrades or eliminated, } \\
\text { the cycle of life is 2-3 } \\
\text { years, the great } \\
\text { equipment upgrades, it } \\
\text { is also required to upgrade } \\
\text { the network bandwidth . }\end{array}$ \\
\hline The environment & $\begin{array}{l}\text { Business environment in the } \\
\text { network environment, and it can } \\
\text { ensure that it is clean and sanitary, }\end{array}$ & $\begin{array}{l}\text { It can be used for network } \\
\text { and non-network } \\
\text { environment, the }\end{array}$ \\
\hline
\end{tabular}

\begin{tabular}{|l|l|l|}
\hline & $\begin{array}{l}\text { easy to clean of the environment } \\
\text { it can keep a long time clean of } \\
\text { the working environment . }\end{array}$ & $\begin{array}{l}\text { environment is extremely } \\
\text { bad, not easy to clean, } \\
\text { and it is a huge workload } \\
\text { for cleaning. }\end{array}$ \\
\hline $\begin{array}{l}\text { The conservation } \\
\text { of Energy }\end{array}$ & $\begin{array}{l}\text { The thin client Power only 5 - 10W, } \\
\text { the consumption is very small. }\end{array}$ & $\begin{array}{l}\text { The consumption of pc } \\
\text { desktop power is huge. }\end{array}$ \\
\hline
\end{tabular}

\subsection{Virtual Resource of Cloud Desktop Management}

The key technologies of cloud data center Virtual resource management : resource virtualization, the virtual machine deployment provided by resource , resource scheduling, and virtualized migration. The structure of its resource management is shown in Figure7 


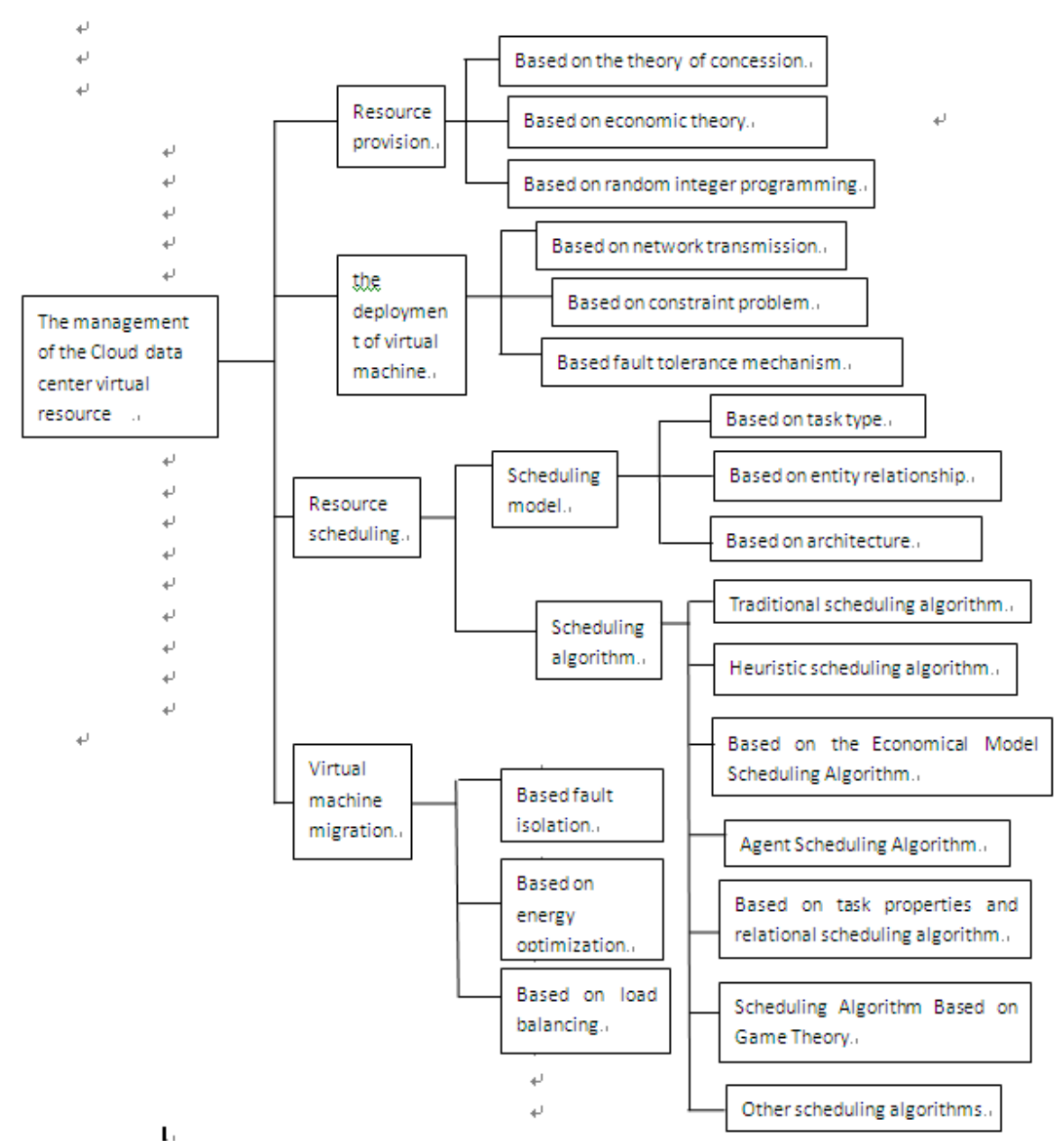

Figure. 7. The virtual resource management structure of cloud desktop

\subsection{Resource allocation strategy and scheduling algorithm of cloud desktop management}

\subsubsection{The allocation strategy of cloud resource}

Cloud computing technology enables the allocation of resources on demand and increases the system utilization and overall performance. Resource allocation strategies need to meet the various parameters, such as throughput, delay, response time and so on. Due to the limited resources, heterogeneity of resources, geographical constraints, the dynamics of the environment and resource requirements, we need an effective resource allocation system to provide users with the best resources. To this end, we propose a model of cloud resource allocation ${ }^{[22]}$.

For the free resource there are $\mathrm{N}$ user requests, the $\mathrm{t}(1<=\mathrm{t}<=\mathrm{n})$ user requests the cloud system to provide $\mathrm{K}(\mathrm{t})$ VMs so that $\mathrm{R}(\mathrm{t})$ is the maximum of network distance between the virtual machines for the $\mathrm{t}$ user, the network diameter $\mathrm{R}(\mathrm{t})=\max \{\mid$ eij $(\mathrm{t}) \mid: 1<=\mathrm{i}, \mathrm{j}<=\mathrm{K}(\mathrm{t})\}$ is optimized to minimize the sum of the virtual machine network diameters of each user. The objectives are as follows:

$$
\text { Minimize } \sum_{\mathrm{i}=1}^{\mathrm{n}} \mathbf{R}(\mathrm{t})
$$




\subsubsection{Cloud resource allocation algorithm}

Here we study a cloud resource allocation method based on "ant colony algorithm" [19]. Ant colony algorithm is a kind of bionic algorithm which is similar to the path of the natural ants. The ant colony algorithm illustrates the optimal allocation strategy of resources by describing the question how the ants find the optimal route. The optimal allocation model of resource allocation is constructed by using the optimal allocation solution of the ant colony algorithm. The algorithm is applied to the problem of cloud service resource allocation. The effective allocation of terminal resources is solved effectively by the cloud server, avoiding the waste of resources.

\section{Construction and Application of Cloud Security Management Model}

\subsection{Building a Management Model of Cloud Security}

The relationship between cloud computing models depends on its three basic core architectures: IaaS virtualization technology, PaaS distributed technology, and SaaS online software technology. These three core architectures together constitute the basic cloud computing security reference model, at all levels play an important role. The relationship between them is shown in Figure $8^{[1]}$.

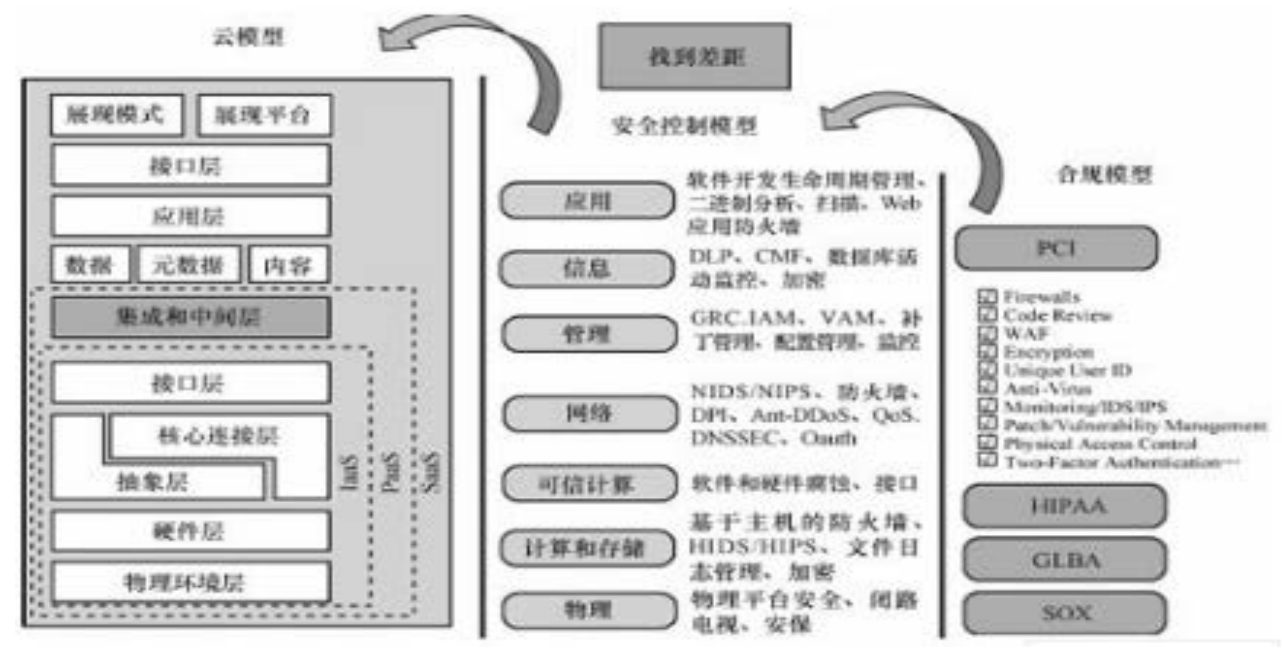

Figure. 8. The security reference model of cloud computing

IaaS covers hardware platforms such as servers, networks, storage, and infrastructure. PaaS is located above IaaS and is provided to current users through the Internet using distributed software development, testing, and deployment environments as services. ${ }^{[9]} \mathrm{PaaS}$ can be built on virtualized resource pools in IaaS and also can be built on physical infrastructure in data centers. SaaS is based on the Internet to provide a software service application model that passes the server software to users through the browser, which can be used by users online. ${ }^{[4]}$ The cloud security architecture is important at all levels, and its core needs remain the protection of the confidentiality, integrity, availability, and privacy of applications and data ${ }^{[2]}$. The content of cloud computing in the three security layers of data, application and virtualization (see table 3), and its corresponding coping strategies and technologies are worthy of in-depth study ${ }^{[10]}$.

Table 3. The Content Matrix of Cloud Security 


\begin{tabular}{lc}
\hline Cloud security level & Cloud Content \\
\hline Data Security & Data Transmission, Data Isolation, Data Retention \\
Application Security & End User Security, SaaS Security, PaaS Security, IaaS Security \\
Virtualization of Security & Virtualization Software,Virtual Server \\
\hline
\end{tabular}

\subsection{The cloud applications of teaching and management in the training center}

Combined with the training center operation of Changchun University of Finance and Economics, through the cloud terminal management platform, teachers and students can undertake courses and make an appointment through the management platform, such as training room use appointment and opening time booking and other functions. The teacher can also conduct student attendance in the platform, which greatly facilitates the development of teaching and meets the needs of the management of the training room. In the security management, cloud server unified security configuration and risk prevention through cloud server, avoiding the problem of low efficiency of traditional single investigation and killing. Cloud server by customizing all kinds of templates compared with the traditional way of computer room clones to be more efficient, for example: for the paperless examination system template issued to cloud desktop, on the normal teaching system template issued back to the state of the class. The use of teaching software greatly improves students' practical ability and manipulative ability, such as: cloud server saves a lot of time for software installation; there are dozens or more of the teaching software installed on the server side; it is more intuitive to access online teaching through the cloud desktop in B/S mode. In summary, cloud desktop is widely used in both teaching and management, which makes up for some disadvantages of traditional PC desktop. See Figure 9 for details.

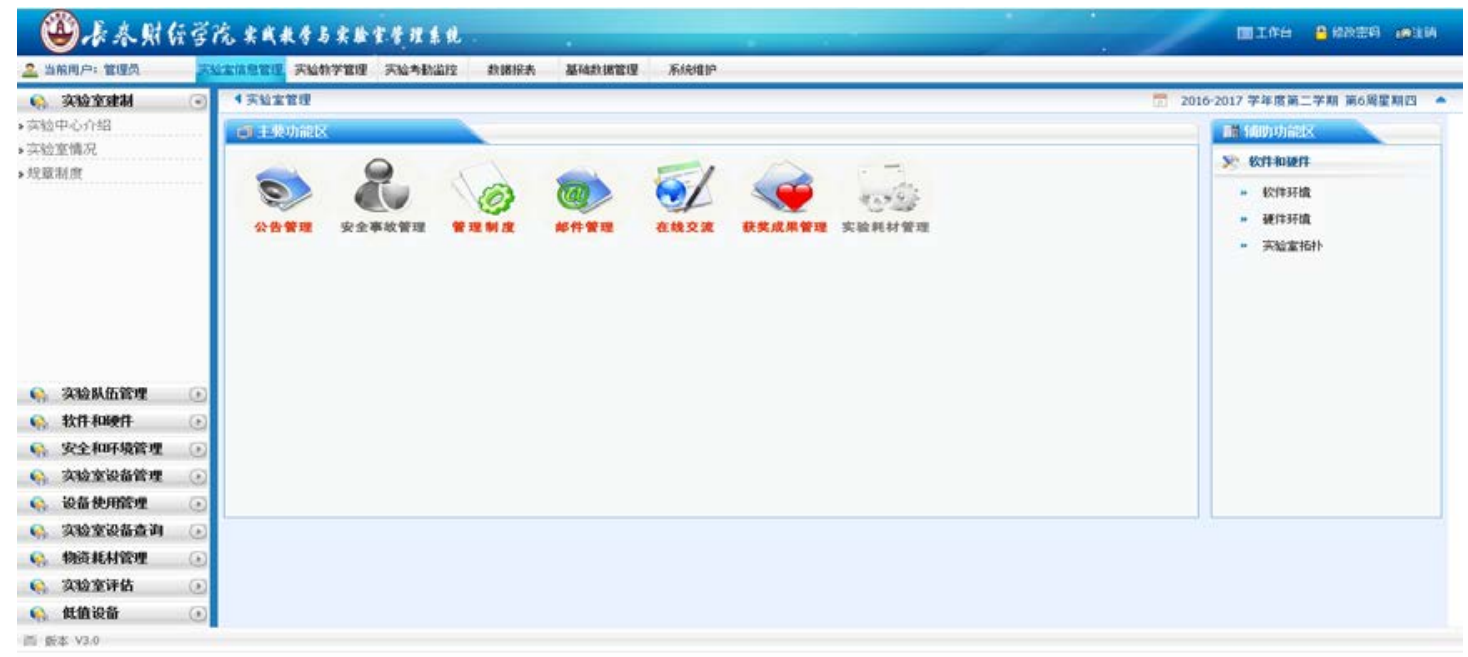




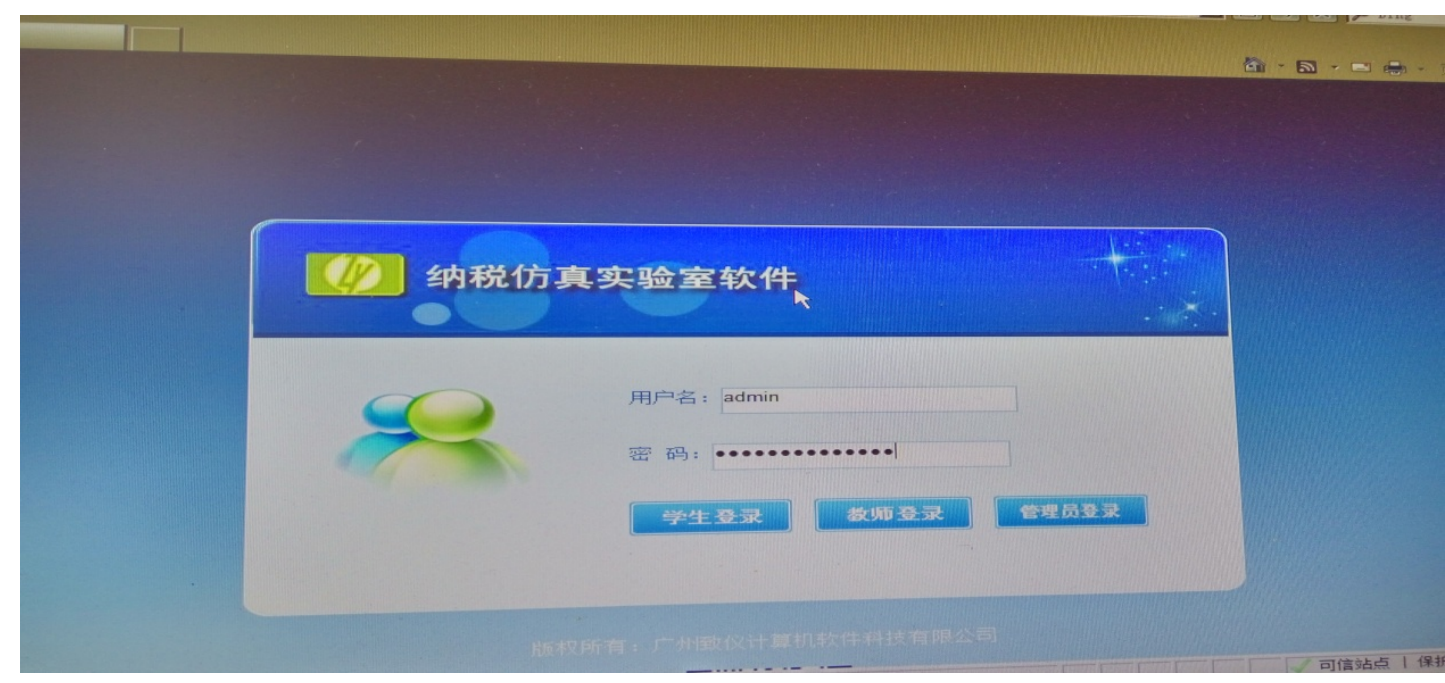

Figure. 9. The applications of cloud laboratory management platform and simulation teaching software

\section{Summary and outlook}

Through the construction of the actual training room and the research of some problems that may exist during the use of virtual simulation training center in colleges and universities, the paper give practice from cloud desktop platform construction, the key technology of cloud desktop management, cloud desktop management strategy, algorithm and scheduling and the construction of cloud security model from several aspects, the test application was carried out through the cloud in the teaching and management of the training center. Research and test results show that the use of cloud desktop technology can effectively solve the traditional PC mode to the disadvantages of the teaching and management, cloud desktop technology for teaching and curriculum design provides a great convenience in resource management, risk monitoring, behavior management etc. By introducing a cloud desktop technology, to engage in a variety of training rooms $\mathrm{B} / \mathrm{S}$ software teaching makes the university keep ahead in the same level of colleges, at the same time to save cost and improve the quality of teaching play an important role.

In the future, the research should focus on remote control management of cloud servers, cloud network security, dynamic allocation and recycling of cloud resources. Apply cloud security protection to campus network security management, and make efforts to become more intelligent and platform.

\section{Acknowledgement}

The authors wish to express their gratitude to the national spark program project: Precise operation technology integration and demonstration of corn (No.2015GA660004) for its generous support of this work.

\section{References}

[1] Song Wenchao, Wang Ye, Huang Yong, Liu Zengshou. Simulation of cloud intrusion detection model in cloud computing network under large data environment [J]. West China Science and Technology, 2015, (08): 86-88.

[2] Lin Chuang, Su Wenbo, Meng Kun, Liu Qu, Liu Weidong. Cloud computing security: 
architecture, mechanism and model evaluation [J]. Journal of Computer Science, 2013, (09): 1765-1784.

[3] Xu Yingying, Gao Fei, Shang Fengying, Zhu Junli. New Cloud Security Solution and Its Key Technology [J]. Huazhong University of Science and Technology (Natural Science Edition), 2012, (S1): 74-78.

[4] Ji Yimu, Kang Jiabang, Pan Qiaoyu, Kuang Zizhuo. A cloud computing security model and architecture design research [J]. Information Network Security, 2012, (06): 6-8 + 22.

[5] Gong Chengqing. Based on artificial intelligence network intrusion detection system design [J]. Journal of Nanning Vocational and Technical College, 2009,05: 98-100.

[6] Yuan Yuan. Artificial Intelligence and Network Security [J]. Neijiang Technology, 2009,12: $103+172$.

[7] Xiao Tao, He Huaiwen, Liang Ruishi. Desktop cloud in the university computer laboratory application [J]. Laboratory Science, 2015, (01): 82-84 + 88.

[8] Ning Xiangyan, Zhang Shunyi. Network security status and technology development [J]. Journal of Nanjing University of Posts and Telecommunications (Natural Science Edition), 2012,05: 49-58. [9]Vinothkumar Muthurajan, Balaji Narayanasamy, Xinyi Huang.An Elliptic Curve Based Schnorr Cloud Security Model in Distributed Environment[J].The Scientific WorldJ ournal, 2016, 2016:.[J].The Scientific WorldJ ournal, 2016, 2016(2016):1-8

[10]XUE Haiwei, ZHANG Yunliang, GUO Zhien, DAI Yiqi.A Multilevel Security Model for Private Cloud[J].Chinese Journal of Electronics, 2014, 02:232-235.[J].Chinese Journal of Electronics, 2014, 02(02):232-235 .

[11] Hu Dongxing. Based on artificial intelligence information network security situational awareness technology [J]. Information and Communication, 2012,06: 80-81.

[12] Chu Mei-fang.Study on key technology of network security management based on artificial intelligence theory [J] .Computer CD-ROM Software and Application, 2012,23: 95 + 108.

[13]Gao Zhan,]Design and Implementation of Campus Network Security Management System in Grid Environment [J]; Journal of University of Electronic Science and Technology of China;

[14] He Wenhua, Chen Zhigang. Network security status analysis and development trend [J]. Communication Technology, 2007,10: 30-33.

[15]Debashis Basak, Rohit Toshniwal, Serge Maskalik, Allwyn Sequeira.Virtualizing networking and security in the cloud[J]. ACM SIGOPS Operating Systems Review, 2010, 44(4):.[J].ACM SIGOPS Operating Systems Review, 2010, 4(44):86-94

[16]Yanan Chang, Zhiyong Zhang, Jian Wang.A Security Protocol for Trusted Access to Cloud Environment[J]. Recent Advances in Electrical \& Electronic Engineering, 2015, 8(2):.[J].Recent Advances in Electrical \& Electronic Engineering, 2015, 02(08):1-1 .

[17] Wang Tianming, Liu Shulin. Cloud desktop technology in the construction of educational information[J] .Computer CD-ROM Software and Application, 2015, (02): $228+230$.

[18] Wu Yuanyuan. Cloud desktop technology in the computer room management application [J] .Jilin University of Engineering Technology, 2015, (10): 94-96.

[19] MIAO Pei. Ant colony optimization algorithm in cloud computing resource allocation on the application [D]. Shandong Normal University, 2015.

[20]Han XiangYu. Design and Implementation of Cloud Desktop Management Platform Based on Virtualization [D]. Beijing Jiaotong University, 2015.

[21] Addis, Bernardetta, Ardagna, Danilo, Panicucci, Barbara, Squillante, Mark S, Zhang, Li.A 
Hierarchical Approach for the Resource Management of Very Large Cloud Platforms[J]. IEEE Transactions on Dependable and Secure Computing, 2013, 10(5):.[J].IEEE Transactions on Dependable and Secure Computing, 2013, 05(10):253-272

[22]Jie Zhang, Zhi Jia Xu, Yuan Li.An Optimal Resource Allocation Method for Aircraft Subassembly System Based on Graphic Ant Colony Algorithm[J].Advanced Materials Research, 2011, 1035(156):.[J].Advanced Materials Research, 2011, 156(1035):1397-1403

[23]Heng Li, Li Ping Wang, Guo Shun Li, Zhu Xiong Liu.The Industry Management System Based on Virtualization and Cloud Computing[J].Advanced Materials Research, 2012, 1693(488):.[J].Advanced Materials Research, 2012, 488(1693):782-786.

[24] Yan Tao, Li Dan. Virtual cloud desktop technology research and implementation [J]. Journal of Chengdu University (Natural Science Edition), 2013, (02): 145-147 + 155.

[25] Pan Fu. Cloud computing security model and management [J]. Electronic Technology and Software Engineering, 2013, (16): 250-251.

[26] Zhu Jiang. On cloud computing security model and management [J]. Electronic Technology and Software Engineering, 2013, (16): 253.

[27]Hua xiahan, chung joon, Hu Wenxin. Ant colony optimization based on cloud computing environment resource allocation algorithm [J]. Journal of east China normal university (natural science edition), 2010. (01) : 127-134.

[28]Huang Jun, Wang Qingfeng zhi-qin liu, Wang Yaobin. Ant colony algorithm is based on resource state of cloud computing task allocation [J]. Computer engineering and design, 2014, (9) : 3305-3309.

[29]Si Ping Liu.Research on Cloud Computing Strategy Based on Security Model[J].Applied Mechanics and Materials, 2014, 3468(644):.[J].Applied Mechanics and Materials, 2014, 644(3468):1835-1839.

[30]Gan sen Zhao, Chun ming Rong, MartinGiljeJaatun, FrodeEikaSandnes.Reference deployment models for eliminating user concerns on cloud security[J].The Journal of Super computing, 2012, 61(2):337-352.

[31]LienDeboosere, BertVankeirsbilck, PieterSimoens, $\quad$ FilipTurck, BartDhoedt,PietDemeester.Efficient resource management for virtual desktop cloud computing[J].The Journal of Superc omputing, 2012, 62(2):.[J].The Journal of Super computing, 2012, 62(2):741-767.

[32] Jiang Fan jun. Cloud desktop technology in the application of the computer teaching management in colleges and universities [D]. Donghua university, 2016.

[33]Wang Rui Na. Cloud desktop platform based on virtual technology in the teaching the application [J]. Journal of foshan institute of science and technology (natural science edition), 2016, (3) : 56-60.

[34] Wu Jia Hui. Analyze the cloud desktop technology application in university training rooms management [J]. Journal of electronic technology and software engineering, 2016, (10) : 178.

[35]Wang Zhi Gang Gao Yong, Wang Chen Yang. A desktop cloud build campus network office platform based on the application study [J]. Journal of network security technology and applications, 2016, (10) : 103-104. 